\title{
INTEGRATION OF BIODIESEL AND BIOGAS PLANTS FOR COST EFFECTIVE BIOFUEL GENERATION
}

\section{K.HARIBABU \& N.AZHAGESAN}

Centre for Alternate fuel, Cape Institute of Technology, Levengipuram, Tamil Nadu, India

\begin{abstract}
Bio fuels such as biogas and biodiesel attract increasing attention all over the world as a substitute or mixture for fossil fuels in automobiles. Transesterification is the process that is used for producing biodiesel which is accepted worldwide because of its efficiency. Transesterification is the process done for decreasing the viscosity of the vegetable oil. In this paper, we have used Transesterification of cottonseed oil to produce biodiesel. The cost of production of one liter of biodiesel from cottonseed oil is thrice the cost of the diesel per liter. The byproducts of Transesterification process are glycerol and methyl ester water-wash. Both of the byproducts are good source of Methanol content which can easily be converted into methane gas or Biogas (CH4). Also, the cottonseed from which the oil is extracted can be used for producing biogas. In this paper, the laboratory experiments for Integrating Biodiesel and Biogas Plants are studied quantitatively in detail. By integrating both biodiesel and biogas plant, it is a way of reducing the cost of biodiesel which can boost the use of biodiesel in future.
\end{abstract}

KEYWORDS: Biodiesel, Biogas, Transesterification, Glycerol, Methyl Ester Wash \& Water

Received: Jul 18, 2017; Accepted: Aug 08, 2017; Published: Aug 16, 2017; Paper Id.: IJMPERDAUG201741

\section{INTRODUCTION}

Transportation system is like the vein of the world, which helps in transferring goods from one place to another. The fossil fuels are the main energy providing medium that has been used on almost all the prime movers. The fossil fuel deposition on the earth is decreasing daily and at the same time the biodiesel fuels are increasing attention worldwide. Environmental concerns and energy crisis of the world has led to the search of viable alternatives to the fossil fuel [1]. Different types of engines using fossil fuels are widely used for different application in industrial power plants, transportation, agriculture etc. The environmental pollution caused by these engines becomes a major concern throughout the world. They produce smoke, particulate matter, oxides of nitrogen (NOx) Oxides of carbon (CO\&CO2) and unburnt Hydrocarbon [2]. Biodiesel is one of the alternative fuels that can be used as a substitution for diesel or as a blend with diesel in order to use it on diesel engines. Biodiesel can be produced from vegetable oils using various methods like micro emulsification method, microwave method, pyrolysis and Transesterification. The Transesterification got global attraction among all the processes as it gives maximum efficiency. The Transesterification is actually a process for decreasing the viscosity of the vegetable oil. Methanol is the usually used alcohol since it is of low cost compared to other alcohol [3]. The production of ester from vegetable oil is a costly process which can reach up to Rs. 250 per litre on varying market values of used substances.

Transesterification process gives two by-products (Glycerol and Methyl ester wash water) which are not much used on the market. Both Glycerol and Methyl wash water are good in methanol content. So the production of biogas from these by-producers is possible [4].The biogas can be produced by Anaerobic digestion which will breakdown 
waste and produce a useful by-product biogas that can be used instead of LPG. Temperature is an important factor that influences microbial activity. Anaerobic digestion can be carried out at three different temperature range, which are psychrophilic (below $\left.25^{\circ} \mathrm{C}\right)$, mesophilic $\left(30-42^{\circ} \mathrm{C}\right)$ and thermophilic $\left(43-55^{\circ} \mathrm{C}\right)$. Anaerobic digestion is normally carried out under mesophilic temperature. And the reason is that it is difficult to achieve the thermophilic temperature naturally and if going for psychrophilic temperature the production rate of biogas will be minimum because of the low temperature. For maximum biogas generation the temperature variation should be kept in between $+/-2^{0} \mathrm{C}$ [6].

Now-a-days the rate of production of biodiesel is increasing, and a large volume of by-products are being wasted without any use. This paper deals with the use of by-products in an effective way in order to produce another fuel that is biogas and compensating its cost in biodiesel.

\section{AIMS AND OBJECTIVES}

- $\quad$ Production of biodiesel from the cottonseed oil using varying methanol ratios.

- Collecting the by-products (Glycerol and Methyl ester wash water) and comparing the effect of Glycerol in generation of biogas.

- Cost analysis on the production of the biodiesel and compensating the cost of the biodiesel with the profit from the biogas.

\section{Sources of Raw Materials}

The cottonseed oil was purchased from Chandrakant Co.PVT LTD Chennai. The alcohol (Methanol) and the catalyst Pottassium Hydroxide $(\mathrm{KOH})$ was purchased from a local Chemical shop near Nagercoil. The laboratory experimental apparatus for biogas production was made from the college research laboratory. The cottonseed oil was tested from Abitek Laboratories for getting properties of the oil (Table-1).

Table 1: Properties of Cottonseed Oil

\begin{tabular}{|l|c|}
\hline \multicolumn{1}{|c|}{ Properties } & Values \\
\hline Kinematic Viscosity @ $40^{\circ} \mathrm{C}$ & $37.7 \mathrm{cst} / \mathrm{second}$ \\
\hline Kinematic Viscosity @ $100^{0} \mathrm{c}$ & $4.9 \mathrm{cst} / \mathrm{second}$ \\
\hline Density & $913 \mathrm{Kg} / \mathrm{m}^{3}$ \\
\hline Specific heat and specific gravity & $0.919 \mathrm{~g} / \mathrm{cc}$ \\
\hline Calorific value & $3581.06 \mathrm{kcal} / \mathrm{kg}$ \\
\hline Saponification number & 190 \\
\hline Flash point & $197^{0} \mathrm{c}$ \\
\hline Cloud point & $1.4^{0} \mathrm{c}$ \\
\hline Fire point & $220^{\circ} \mathrm{c}$ \\
\hline Cetene number & 37 \\
\hline Acid value & $9.50 \mathrm{mg} / \mathrm{g}$ \\
\hline Iodine value & $93.07 \mathrm{mg} / \mathrm{g}$ \\
\hline Molecular weight & $19.97 \mathrm{~g} / \mathrm{mol}$ \\
\hline
\end{tabular}

\section{Experimentation and Methods}

The whole project was completed by the following three phases.

- Biodiesel production from the cottonseed oil using Transesterification process.

- Collecting the by-products Glycerol and Methyl Ester wash Water after Transesterification process. 
- Producing Biogas from the Transesterification by-products and comparing the results with the traditional biogas plant (Laboratory scale).

\section{Experiment Phase-I}

In the first phase of the experiment, the esterification of the cottonseed oil was carried out using Transesterification reaction. Each production was experimented and finally $500 \mathrm{ml}$ of cottonseed oil, $4 \mathrm{~g} \mathrm{KOH}$, and $150 \mathrm{ml}$ methanol is the best suitable ratio for producing biodiesel from Cottonseed oil.

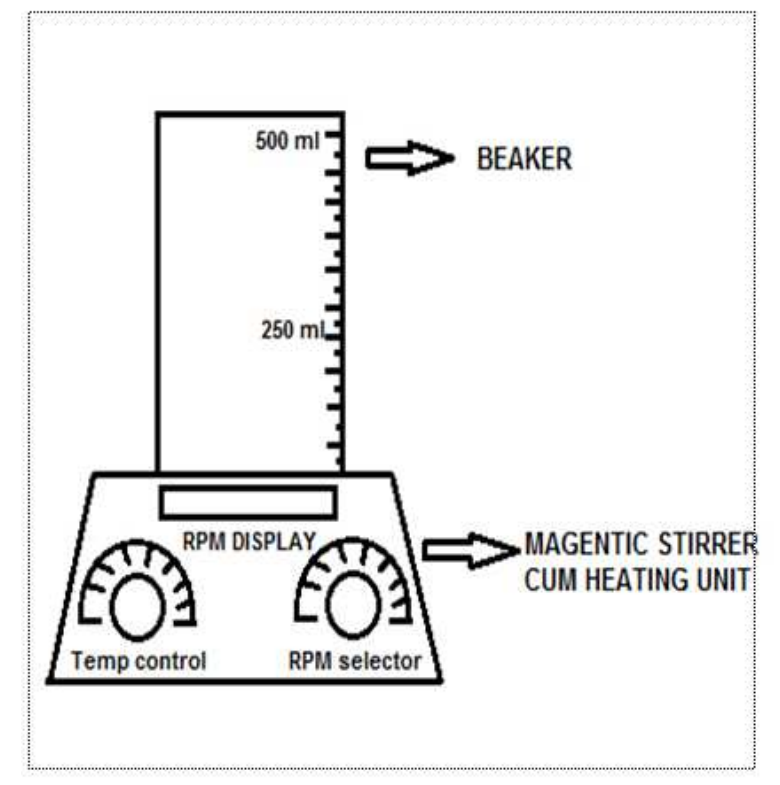

Figure 1: Apparatus for Transesterification Reaction

Initially the cottonseed oil was taken in a beaker and heated using a Heater cum magnetic stirrer apparatus up to $100^{\circ} \mathrm{C}$ for evaporating the water particles.

At the same time the $\mathrm{KOH}$ and Methanol was stirred well on another Magnetic stirrer for adding to oil later. The preheated oil was then allowed to cool down to $50^{\circ} \mathrm{C}$ and at that time, the already prepared mixture of $\mathrm{KOH}$ and Methanol was added into the oil. The temperature was kept on constant $50^{\circ} \mathrm{C}$ which is the best temperature range for Transesterification reaction. The cottonseed oil and methanol $+\mathrm{KOH}$ mixture now turns to milky white colour. Then the magnetic stirrer was turned ON and the RPM was set above $1300 \mathrm{rpm}$. After two hours the mixture turns to transparent brown colour. Now the stirring and heating was turned OFF and the whole solution was collected to a separating funnel. It takes 24 hours for the complete separation of Glycerol and Ester.

\section{Experiment Phase-II}

The next day the Glycerol and Ester were separated from the separating funnel and the ester was then washed using hot water and separated again in separating funnel, to get the clean ester and the methyl ester wash water. The cost of each materials used for producing 1 litre of biodiesel from cottonseed oil is given in Table-2.

Table 2: Cost of Materials for Producing 1 Litre Ester

\begin{tabular}{|l|c|c|}
\hline \multicolumn{1}{|c|}{ Item } & Quantity & Cost in Rupees \\
\hline Cottonseed oil & 1 Litre & 80 \\
\hline Methanol & $250 \mathrm{ml}$ & 160 \\
\hline
\end{tabular}




\begin{tabular}{|l|c|c|}
\hline KOH & $10 \mathrm{~g}$ & 5 \\
\hline Miscellaneous & -------- & 5 \\
\hline \multicolumn{2}{|c|}{ Total } & $\mathbf{2 5 0}$ \\
\hline
\end{tabular}

In a laboratory scale, 250 rupees is the production cost for 1 litre of ester. Thus the cost for different blends of Ester and diesel were prepared. The cost for each blend is given in Table-3. The cost of diesel per litre was taken as Rupees 60 .

Table 3: Cost of Different Blends of Biodiesel

\begin{tabular}{|c|c|c|c|}
\hline Blend & Diesel Qty & Ester Qty & Cost \\
\hline B10 & $900 \mathrm{ml}$ & $100 \mathrm{ml}$ & 79 \\
\hline B20 & $800 \mathrm{ml}$ & $200 \mathrm{ml}$ & 89 \\
\hline B30 & $700 \mathrm{ml}$ & $300 \mathrm{ml}$ & 98 \\
\hline
\end{tabular}

The most commonly used blend is B10 which costs Rs79 per litre, which is since unaffordable the diesel is available in rupees 60 per litre. So, to decrease the cost of the biodiesel, an alternative should be found out. The third phase of the experiment was for finding out the cost savings by producing Biogas from by-products of the Phase-I and Phase-II experiments.

\section{Experiment Phase-III}

In the third phase of the experiment, we made three apparatuses for producing biogas. The anaerobic digestion of the bio manure can give the maximum amount of methane production [7]. The laboratory apparatus we made has three parts each: Digester, Gas collector and Water Column respectively [8]. The schematic diagram of the apparatus is shown in figure-2.

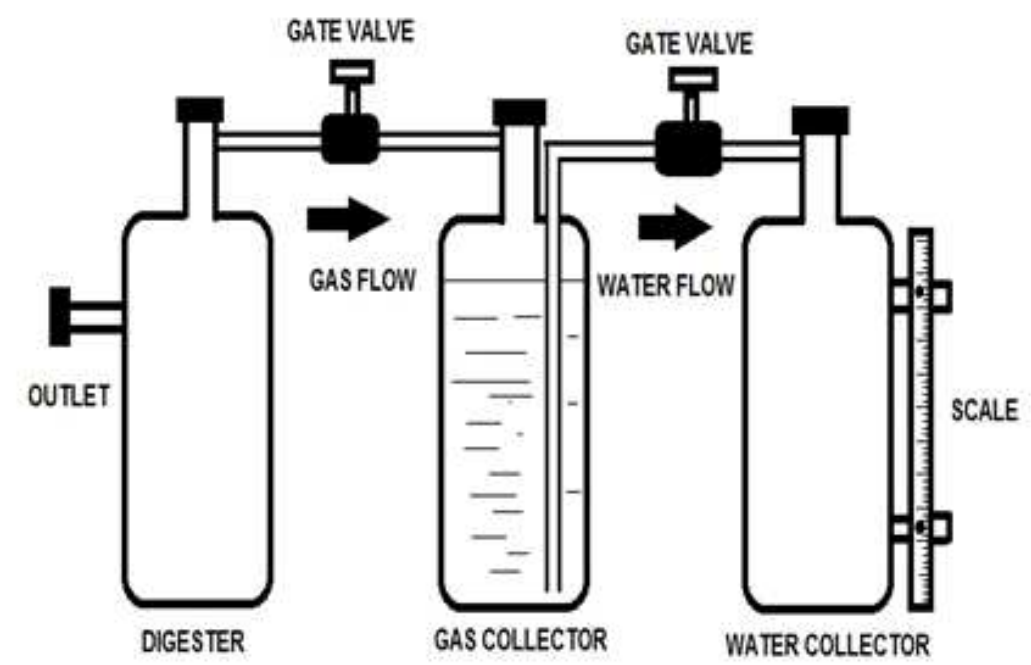

Figure 2: Biogas Producing Apparatus in Laboratory Scale. Size of Each Column is 20L

In the project we used three apparatus of the same design for producing biogas. The digesters of the three apparatus are filled with different ratios of by-products in order to check the biogas production rate individually.

\section{Apparatus-I}

The digester of the apparatus-I is filled with cow dung and water in 1:1 ratio. 


\section{Apparatus-II}

The digester of the apparatus-II is filled with cow dung, water and $20 \mathrm{ml}$ Glycerol (1\% of the digester volume).

\section{Apparatus-III}

The digester of the apparatus-III filled with Crushed-dried cottonseed, water, methyl ester water wash.

\section{Gas production on Apparatus I, II \& III}

On each of the digester, the gas was generated and it created a pressure above the surface of the water in the next tank (Gas collector), this forces the water to flow to third tank (water column) according to Pascal's Law. The water level on the water column is noted daily two times from all the three apparatus to get the quantity of rise of water.

\section{RESULTS AND DISCUSSIONS}

Cotton was cultivated in large amount in northern India, which stands as the main living income for many people. By producing biodiesel and biogas from biodiesel by-products and cottonseed can help in boosting cultivation of cotton which can improve the life style of many people who live depending on cotton cultivation.

Table 4: Amount of Ester and Glycerol Extracted from Cottonseed Oil

\begin{tabular}{|c|l|l|l|l|}
\hline Oil $(\mathbf{m l})$ & Alcohol $(\mathbf{m l})$ & Catalyst $(\mathbf{g})$ & Ester $(\mathbf{m l})$ & Glycerol $(\mathbf{m l})$ \\
\hline Cottonseed oil $(1 \mathrm{~L})$ & $150(\mathrm{ml})$ & KOH $(10 \mathrm{~g})$ & $950(\mathrm{ml})$ & $200(\mathrm{ml})$ \\
\hline
\end{tabular}

Table 5: Batch Wise Production Details of Ester using Cottonseed Oil with Varying Methanol Quantity

\begin{tabular}{|l|c|c|c|c|c|c|c|}
\hline Batch & Cottonseed oil & Catalyst & Methanol & Glycerol & $\begin{array}{c}\text { Ester before } \\
\text { washing }\end{array}$ & $\begin{array}{c}\text { Ester after } \\
\text { washing }\end{array}$ & $\begin{array}{c}\text { Ester after } \\
\text { heating }\end{array}$ \\
\hline----- & $(\mathbf{L})$ & $(\mathbf{g})$ & $(\mathbf{L})$ & $(\mathbf{L})$ & $(\mathbf{L})$ & $(\mathbf{L})$ & $(\mathbf{L})$ \\
\hline I & 0.5 & 5 & 0.150 & 0.110 & 0.390 & 0.375 & 0.360 \\
\hline II & 0.5 & 5 & 0.140 & 0.125 & 0.375 & 0.360 & 0.350 \\
\hline III & 0.5 & 5 & 0.130 & 0.140 & 0.360 & 0.355 & 0.345 \\
\hline IV & 0.5 & 5 & 0.120 & 0.150 & 0.345 & 0.330 & 0.325 \\
\hline
\end{tabular}

This can be a solution for common man to run his vehicle in minimum cost with least emission comparing to petroleum products. The integrated laboratory scale production of biodiesel and biogas shows a greater scope for high scale production of such a plant.

\section{Phase-I-Biodiesel Production}

The ester that is produced using cottonseed oil seems to be more transparent and is shows very good properties.

Table-4 shows the amount of Ester and Glycerol extracted from cottonseed oil. In this biodiesel production we varied the Methanol content in the each batch of productions.

Table-5 shows the batch wise production details of ester using cottonseed oil with varying methanol quantity. From our laboratory production scale it is shown that the increase in methanol content increased the rate of ester generation.

The high cost raw material used for biodiesel generation is methanol. So the quantity of methanol using is to be minimized to decrease the cost of biodiesel without affecting the rate of ester generation during transesterification. This was our aim during generation of biodiesel. 
The best methanol quantity that can be used from our experiment is $150 \mathrm{ml}$ for $1000 \mathrm{ml}$ of Cottonseed oil. While the amount of alcohol was increased above 150, the solution turns red and the whole solution become useless.

The different blends of ester and diesel, that is B10, B20 and B30 were tested on Engine to get the performance and emission characteristics of the fuel. The engine performance test and emission test details of the blends are shown in Table-6.

\section{Engine Performance Tests}

\section{Break Thermal Efficiency}

Table-6 shows the Break Thermal Efficiency V/S Load (Kg) results. An increase in BTE with increase in load was observed up to a load level of about $15 \mathrm{Kg}$. Oxygen present in the blends perhaps also helped in complete combustion of fuel at no load and also at partial load conditions. At full load conditions, the change of state from the molecule oxygen to atomic oxygen occurs. Specific gravity of the vegetable oils perhaps also played an important role in affecting the performance of engine at full load levels.

Table 6: Break Thermal Efficiency V/S Load

\begin{tabular}{|l|l|l|l|l|l|}
\hline Blends & \multicolumn{1}{|c|}{$\mathbf{~ K g}$} & \multicolumn{1}{|c|}{$\mathbf{K g}$} & $\mathbf{8 K g}$ & \multicolumn{1}{|c}{$\mathbf{K g}$} & \multicolumn{1}{|c|}{$\mathbf{K g}$} \\
\hline B5 & 12.3 & 18.50 & 27.95 & 32.3 & 35 \\
\hline B10 & 13.6 & 17.76 & 27.11 & 33.29 & 37.14 \\
\hline B20 & 13.4 & 17.2 & 27.01 & 33.1 & 37.37 \\
\hline B30 & 12.9 & 16.48 & 24.87 & 32.52 & 33.53 \\
\hline Diesel & 11.9 & 16.01 & 23.7 & 31.2 & 32.1 \\
\hline
\end{tabular}

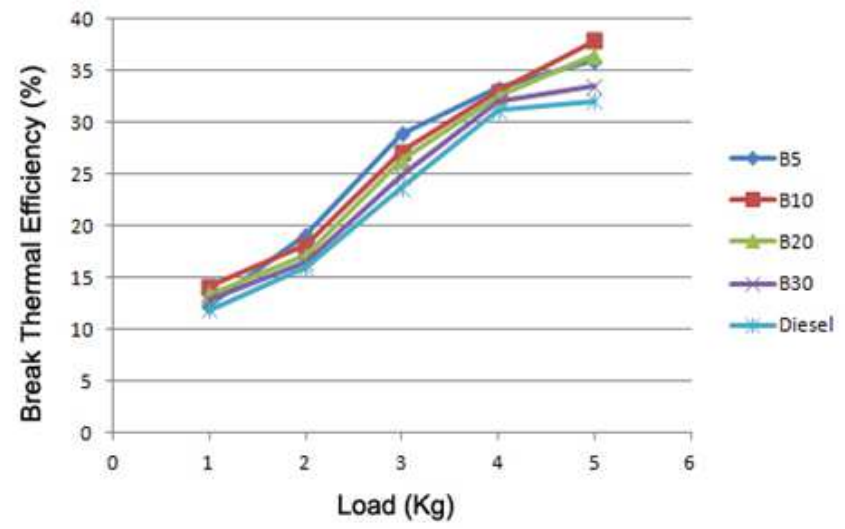

Figure 3: Break Thermal Efficiency V/S Load

\section{Mechanical Efficiency}

Mechanical efficiency is one of the important properties of a fuel. Table-7 shows the Mechanical Efficiency V/S Load $(\mathrm{Kg})$ results. Here, the mechanical efficiency of the biodiesel is increasing with the increasing loading conditions. The Mechanical efficiency of biodiesel is higher than that of the ordinary diesel which is an important finding.

Table 7: Mechanical Efficiency V/S Load

\begin{tabular}{|c|c|c|c|c|c|}
\hline Blends & $\mathbf{0 K g}$ & $\mathbf{4 K g}$ & $\mathbf{8 K g}$ & $\mathbf{1 2 K g}$ & $\mathbf{1 5 K g}$ \\
\hline B5 & 22.6 & 33.74 & 54.33 & 64.28 & 70.53 \\
\hline B10 & 24.8 & 34.05 & 53.78 & 69.62 & 78.62 \\
\hline B20 & 26.1 & 35.02 & 52.12 & 65.7 & 73.9 \\
\hline B30 & 28.3 & 35.66 & 52.85 & 65.7 & 73.9 \\
\hline
\end{tabular}




\begin{tabular}{|l|l|l|l|l|l|}
\hline Diesel & 21.3 & 30.24 & 44.98 & 61.03 & 66.96 \\
\hline
\end{tabular}

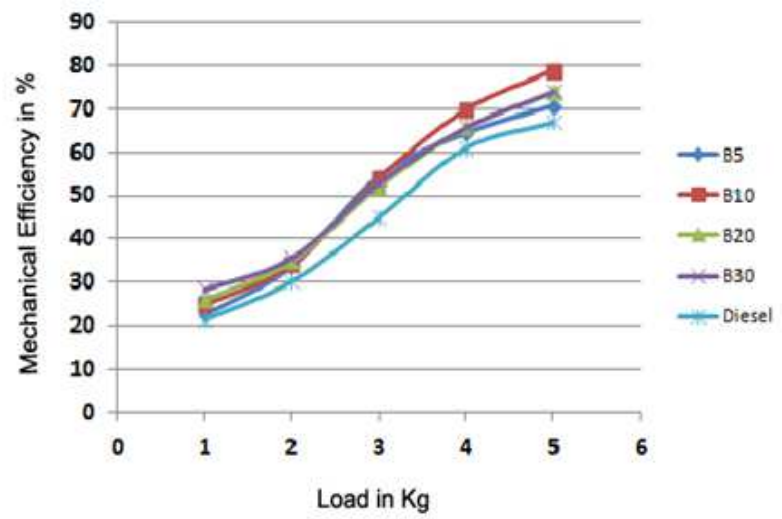

Figure 4: Mechanical Efficiency V/S Load

\section{Fuel Consumption}

Fuel consumption is one of the important parameters of an engine. Fuel consumption on each Load on engine is given in table-8. It was observed that, as the load increases fuel consumption also increases. Fuel consumption of ethyl esters are generally less than that of raw vegetable oils.

Table 8: Fuel Consumption V/S Load

\begin{tabular}{|c|c|c|c|c|c|}
\hline Blends & $\mathbf{0 K g}$ & $\mathbf{4 K g}$ & $\mathbf{8 K g}$ & $\mathbf{1 2 K g}$ & $\mathbf{1 5 K g}$ \\
\hline B5 & 10 & 11 & 14.5 & 18.5 & 21 \\
\hline B10 & 8.5 & 11.5 & 15 & 18 & 20 \\
\hline B20 & 9 & 12 & 15 & 18 & 20 \\
\hline B30 & 8.5 & 12 & 15 & 18.5 & 21 \\
\hline Diesel & 8.28 & 11 & 14.5 & 16.5 & 20 \\
\hline
\end{tabular}

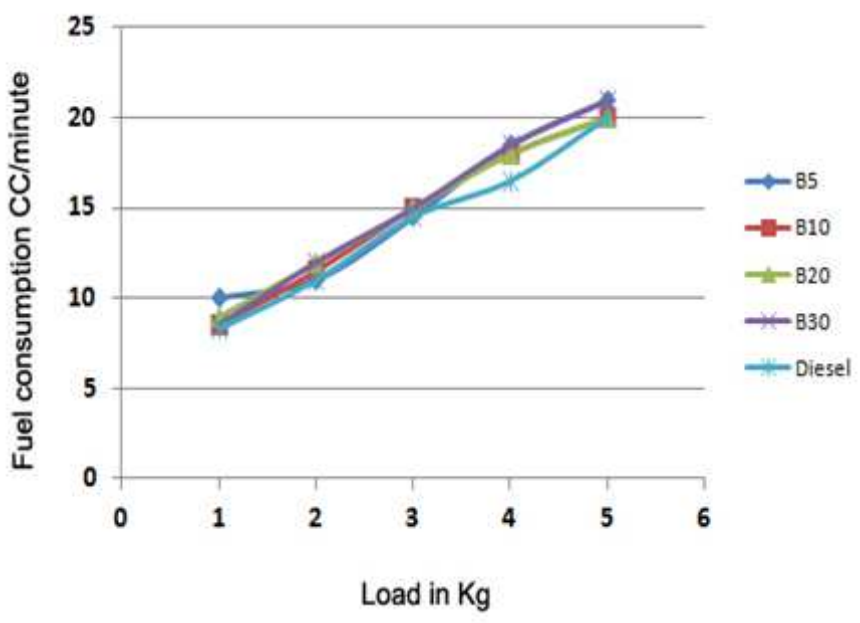

Figure 5: Fuel Consumption V/S Load

\section{Emission Test for Different Blends}

The emission test was conducted for the different blends and for the fossil fuel also. B5 has a higher emission of oxygen and diesel shows the less. Carbon monoxide is also less for B5. 
Table 9: Emission Rate Results in Different Blends

\begin{tabular}{|l|c|c|c|c|c|}
\hline Blends & $\mathbf{O}_{\mathbf{2}}$ & $\mathbf{C O}$ & $\mathbf{N O}$ & $\mathbf{N O}_{\mathbf{2}}$ & $\mathbf{C}_{\mathbf{x}} \mathbf{H}_{\mathbf{y}}$ \\
\hline B5 & 10 & 11 & 14.5 & 18.5 & 21 \\
\hline B10 & 8.5 & 11.5 & 15 & 18 & 20 \\
\hline B20 & 9 & 12 & 15 & 18 & 20 \\
\hline B30 & 8.5 & 12 & 15 & 18.5 & 21 \\
\hline Diesel & 8.28 & 11 & 14.5 & 16.5 & 20 \\
\hline
\end{tabular}

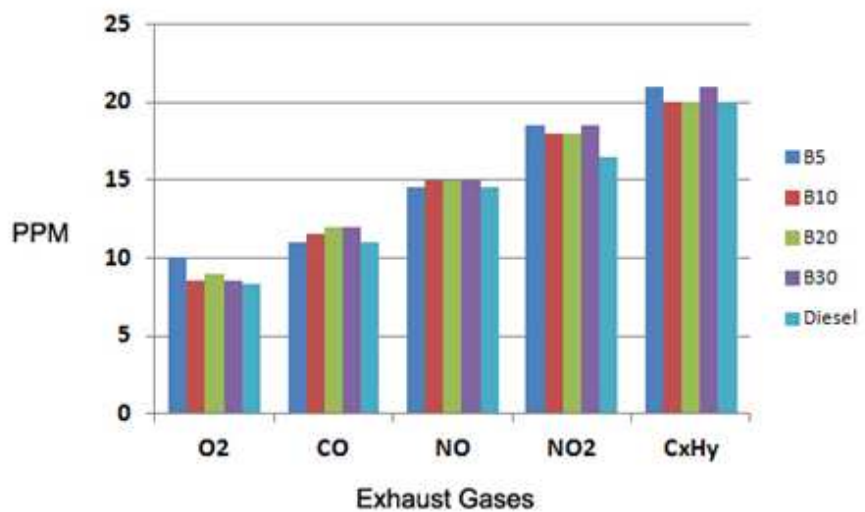

The performance and emission test of biodiesel shows that the biodiesel is a promising alternative fuel for the future. Also from all the blends, B10 has the best characteristics on testing compared to other blends.

\section{Phase-II-Biogas Generation:}

The biogas is generated in three apparatus by using three types of raw materials in its digesters.

\section{Apparatus-I}

The methane generation in apparatus-I is shown in Figure-3. The methane gas generation continues till the $15^{\text {th }}$ day and after that the methane generation is decreased and so the water level is almost same for the next few days.

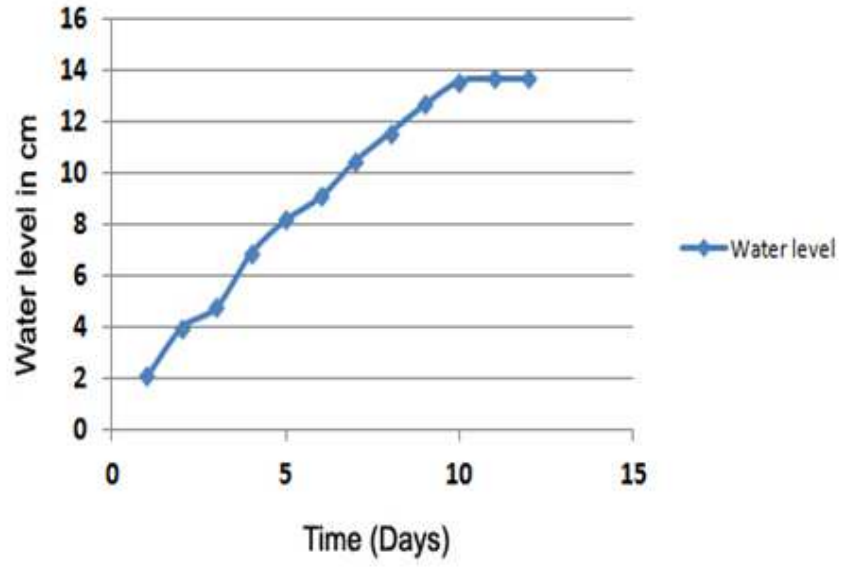

Figure 6: Water Level Rise in Apparatus-I 


\section{Apparatus-II}

The methane generation in apparatus-II is shown in figure-IV. The methane generation in this apparatus is faster, comparing to the apparatus-I due to the addition of the Glycerol in the digester.

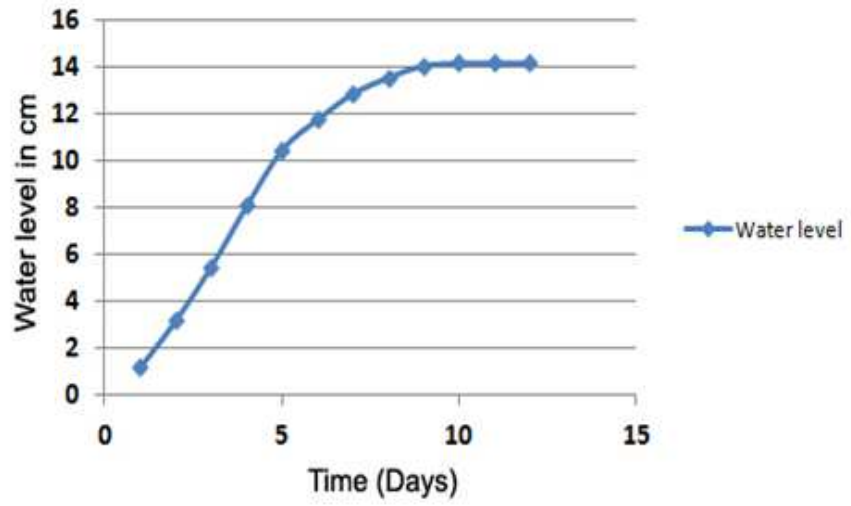

Figure 7: Water Level Rise in Apparatus-II

\section{Apparatus-III}

The methane generation in apparatus-III is lesser. From our readings it is clear that the cottonseed waste can be used to generate methane.

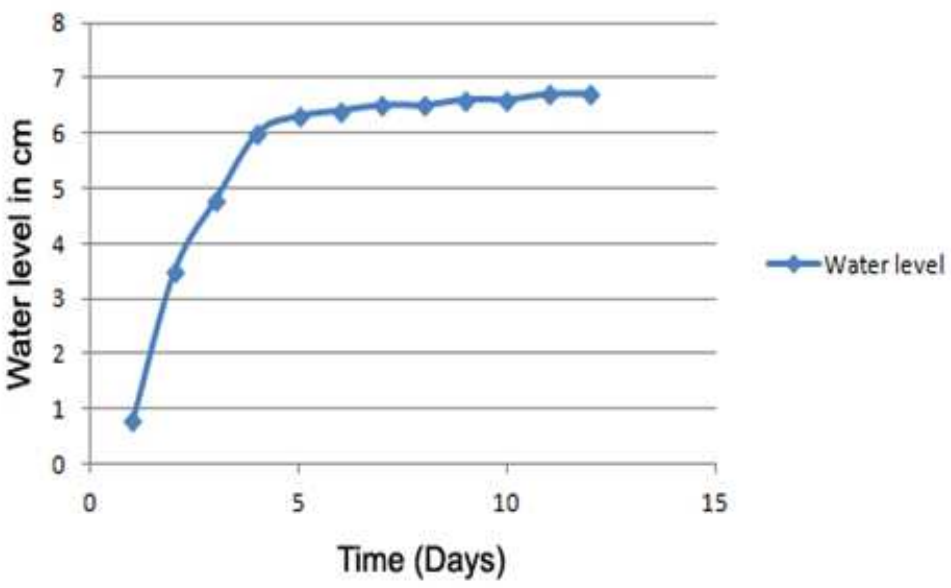

Figure 8: Water Level Rise in Apparatus-III

The gas that is formed up to Day 6 contains the maximum amount of $\mathrm{Co}_{2}$ and least amount of Methane.

\section{Testing Method of Methane Production}

From the all three apparatus, gas was collected from the top of the Gas collector tank using a syringe. The Apparatus-I and Apparatus-II produced a good flame while tested using syringe. The apparatus-III did not produce methane till the sixth day. While checked using the syringe, the gas produced in the Apparatus-III did not produced any flame.

From our experiment it is clear that the methane gas generation from the conventional biogas plants can be 
increased using the addition of Glycerol. Also, by using crushed cottonseed waste, methyl ester wash water and glycerol the biogas can be generated.

The amount of Methane content from the each apparatus was measured from the laboratory by using Gas analyzer. The percentage of different gases in the produced Biogas is given in Table-7.

Table 10: Percentages of Different Gases in Biogas

\begin{tabular}{|l|l|c|}
\hline Apparatus & \multicolumn{1}{|c|}{ Gas } & Percentage \\
\hline \multirow{4}{*}{ I } & Methane & $52 \%$ \\
\cline { 2 - 3 } & $\mathrm{CO}_{2}$ & $47 \%$ \\
\cline { 2 - 3 } & $\mathrm{H}_{2} \mathrm{~S}$ & $1 \%$ \\
\hline \multirow{4}{*}{ II } & $\mathrm{Methane}$ & $65 \%$ \\
\cline { 2 - 3 } & $\mathrm{CO}_{2}$ & $34.5 \%$ \\
\cline { 2 - 3 } & $\mathrm{H}_{2} \mathrm{~S}$ & $<0.5 \%$ \\
\hline \multirow{4}{*}{ III } & $\mathrm{Methane}$ & $48 \%$ \\
\cline { 2 - 3 } & $\mathrm{CO}_{2}$ & $51 \%$ \\
\cline { 2 - 3 } & $\mathrm{H}_{2} \mathrm{~S}$ & $1 \%$ \\
\hline
\end{tabular}

From the table it is clear that the addition of the Apparatus-II produced maximum amount of Methane comparing the other apparatus.

Table 11: Water Level Rise in Biogas Apparatus

\begin{tabular}{|c|c|c|c|c|c|c|c|}
\hline Day\& Date & Time & Apparatus-I & $\begin{array}{c}\text { Water level } \\
\text { Rise/Day }\end{array}$ & Apparatus-II & $\begin{array}{c}\text { Water level } \\
\text { Rise/Day }\end{array}$ & Apparatus-III & $\begin{array}{c}\text { Water level } \\
\text { Rise/Day }\end{array}$ \\
\hline \multirow{2}{*}{$\begin{array}{c}31 / 01 / 2014 \\
\text { Friday }\end{array}$} & $11: 20 \mathrm{AM}$ & $0.5 \mathrm{~cm}$ & \multirow{2}{*}{$1.6 \mathrm{~cm}$} & $0.3 \mathrm{~cm}$ & \multirow{2}{*}{$0.9 \mathrm{~cm}$} & $0.3 \mathrm{~cm}$ & \multirow{2}{*}{$0.5 \mathrm{~cm}$} \\
\hline & 04:20 PM & $2.1 \mathrm{~cm}$ & & $1.2 \mathrm{~cm}$ & & $0.8 \mathrm{~cm}$ & \\
\hline \multirow{2}{*}{$\begin{array}{c}01 / 02 / 2014 \\
\text { Saturday }\end{array}$} & $11: 20 \mathrm{AM}$ & $3.2 \mathrm{~cm}$ & \multirow{2}{*}{$0.8 \mathrm{~cm}$} & $2.5 \mathrm{~cm}$ & \multirow{2}{*}{$0.7 \mathrm{~cm}$} & $1.2 \mathrm{~cm}$ & \multirow{2}{*}{$2.3 \mathrm{~cm}$} \\
\hline & 04:20 PM & $4 \mathrm{~cm}$ & & $3.2 \mathrm{~cm}$ & & $3.5 \mathrm{~cm}$ & \\
\hline \multirow{2}{*}{$\begin{array}{c}\text { 02/02/2014 } \\
\text { Sunday }\end{array}$} & $11: 20 \mathrm{AM}$ & $4.5 \mathrm{~cm}$ & \multirow{2}{*}{$0.3 \mathrm{~cm}$} & $4.8 \mathrm{~cm}$ & \multirow{2}{*}{$0.7 \mathrm{~cm}$} & $4.2 \mathrm{~cm}$ & \multirow{2}{*}{$0.6 \mathrm{~cm}$} \\
\hline & 04:20 PM & $4.8 \mathrm{~cm}$ & & $5.5 \mathrm{~cm}$ & & $4.8 \mathrm{~cm}$ & \\
\hline \multirow{2}{*}{$\begin{array}{c}\text { 03/02/2014 } \\
\text { Monday }\end{array}$} & $11: 20 \mathrm{AM}$ & $6.3 \mathrm{~cm}$ & \multirow{2}{*}{$0.6 \mathrm{~cm}$} & $7.4 \mathrm{~cm}$ & \multirow{2}{*}{$0.7 \mathrm{~cm}$} & $5.6 \mathrm{~cm}$ & \multirow{2}{*}{$0.4 \mathrm{~cm}$} \\
\hline & 04:20 PM & $6.9 \mathrm{~cm}$ & & $8.1 \mathrm{~cm}$ & & $6 \mathrm{~cm}$ & \\
\hline \multirow{2}{*}{$\begin{array}{c}\text { 04/02/2014 } \\
\text { Tuesday }\end{array}$} & $11: 20 \mathrm{AM}$ & $7.8 \mathrm{~cm}$ & \multirow{2}{*}{$0.4 \mathrm{~cm}$} & $9.7 \mathrm{~cm}$ & \multirow{2}{*}{$0.8 \mathrm{~cm}$} & $6.2 \mathrm{~cm}$ & \multirow{2}{*}{$0.1 \mathrm{~cm}$} \\
\hline & 04:20 PM & $8.2 \mathrm{~cm}$ & & $10.5 \mathrm{~cm}$ & & $6.3 \mathrm{~cm}$ & \\
\hline \multirow{2}{*}{$\begin{array}{l}05 / 02 / 2014 \\
\text { Wednesday }\end{array}$} & $11: 20 \mathrm{AM}$ & $8.7 \mathrm{~cm}$ & \multirow{2}{*}{$0.4 \mathrm{~cm}$} & $11.2 \mathrm{~cm}$ & \multirow{2}{*}{$0.6 \mathrm{~cm}$} & $6.4 \mathrm{~cm}$ & \multirow{2}{*}{$0 \mathrm{~cm}$} \\
\hline & 04:20 PM & $9.1 \mathrm{~cm}$ & & $11.8 \mathrm{~cm}$ & & $6.4 \mathrm{~cm}$ & \\
\hline \multirow{2}{*}{$\begin{array}{c}06 / 02 / 2014 \\
\text { Thursday }\end{array}$} & $11: 20 \mathrm{AM}$ & $9.8 \mathrm{~cm}$ & \multirow{2}{*}{$0.7 \mathrm{~cm}$} & $12.3 \mathrm{~cm}$ & \multirow{2}{*}{$0.6 \mathrm{~cm}$} & $6.45 \mathrm{~cm}$ & \multirow{2}{*}{$0.05 \mathrm{~cm}$} \\
\hline & 04:20 PM & $10.5 \mathrm{~cm}$ & & $12.9 \mathrm{~cm}$ & & $6.5 \mathrm{~cm}$ & \\
\hline \multirow{2}{*}{$\begin{array}{c}\text { 07/02/2014 } \\
\text { Friday }\end{array}$} & $11: 20 \mathrm{AM}$ & $11.3 \mathrm{~cm}$ & \multirow{2}{*}{$0.3 \mathrm{~cm}$} & $13.2 \mathrm{~cm}$ & \multirow{2}{*}{$0.4 \mathrm{~cm}$} & $6.5 \mathrm{~cm}$ & \multirow{2}{*}{$0 \mathrm{~cm}$} \\
\hline & 04:20 PM & $11.6 \mathrm{~cm}$ & & $13.6 \mathrm{~cm}$ & & $6.5 \mathrm{~cm}$ & \\
\hline \multirow{2}{*}{$\begin{array}{c}08 / 02 / 2014 \\
\text { Saturday }\end{array}$} & $11: 20 \mathrm{AM}$ & $12.2 \mathrm{~cm}$ & & $13.9 \mathrm{~cm}$ & & $6.5 \mathrm{~cm}$ & \\
\hline & 04:20 PM & $12.7 \mathrm{~cm}$ & $0.5 \mathrm{~cm}$ & $14.1 \mathrm{~cm}$ & $0.2 \mathrm{~cm}$ & $6.5 \mathrm{~cm}$ & $0 \mathrm{~cm}$ \\
\hline $09 / 02 / 2014$ & $11: 20 \mathrm{AM}$ & $13.2 \mathrm{~cm}$ & & $14.1 \mathrm{~cm}$ & & $6.6 \mathrm{~cm}$ & \\
\hline Sunday & 04:20 PM & $13.6 \mathrm{~cm}$ & $0.4 \mathrm{~cm}$ & $14.2 \mathrm{~cm}$ & $0.1 \mathrm{~cm}$ & $6.6 \mathrm{~cm}$ & $0 \mathrm{~cm}$ \\
\hline $10 / 02 / 2014$ & $11: 20 \mathrm{AM}$ & $13.7 \mathrm{~cm}$ & & $14.2 \mathrm{~cm}$ & & $6.6 \mathrm{~cm}$ & \\
\hline Monday & 04:20 PM & $13.7 \mathrm{~cm}$ & $0 \mathrm{~cm}$ & $14.2 \mathrm{~cm}$ & $0 \mathrm{~cm}$ & $6.7 \mathrm{~cm}$ & $0.1 \mathrm{~cm}$ \\
\hline $11 / 02 / 2014$ & $11: 20 \mathrm{AM}$ & $13.7 \mathrm{~cm}$ & & $14.2 \mathrm{~cm}$ & & $6.7 \mathrm{~cm}$ & \\
\hline Tuesday & 04:20 AM & $13.7 \mathrm{~cm}$ & $0 \mathrm{~cm}$ & $14.2 \mathrm{~cm}$ & $0 \mathrm{~cm}$ & $6.7 \mathrm{~cm}$ & $0 \mathrm{~cm}$ \\
\hline
\end{tabular}

Table-11 shows the production of Biogas on each apparatus which was noted daily. From the readings it is clear that the production of Biogas on the apparatus-I is not linear and it is increasing and decreasing, but apparatus-II is almost linear and the production rate is not increasing or decreasing suddenly. In the apparatus-III, the biogas is produced instantly and after that the production rate is decreasing.

\section{Cost Analysis}

The cost for producing one litre of biodiesel is around Rs 250 which is costly. The commonly used blend of biodiesel B10 costs Rs.79 which is about 20 rupees more than that of diesel. So this price difference can keep the 
customers away from the biodiesel even it is having benefits. In order to reduce the cost of biodiesel we can compensate the money saved with the produced biogas.

The Methane content in the apparatus-II and Apparatus-III were used for calculating the cost estimation.

Table 12: Cost List of Items in One Cycle of Biogas Production on Apparatus-III

\begin{tabular}{|l|c|c|}
\hline \multicolumn{1}{|c|}{ Item } & Quantity & Cost \\
\hline Glycerol & $20 \mathrm{ml}$ & 0 (By-product) \\
\hline Crushed Cottonseed waste & $10 \mathrm{KG}$ & 0 (By-product) \\
\hline Water & $8 \mathrm{~L}$ & Negligible \\
\hline Methyl ester wash water & $2 \mathrm{~L}$ & 0 (By-product) \\
\hline
\end{tabular}

Apparatus-II produced $65 \%$ of Methane and remaining 35\% contains $\mathrm{H}_{2} \mathrm{~S}$ and $\mathrm{CO}_{2}$. Thus the gas produced can be stored in a temporary storage tank. Then it can be used as a cooking gas or as a fuel to run vehicles. From our experiments the 201 tank fully gets filled within 25 days. Thus the produced volume of Methane will be about 9.6 1.

The calculations for the analysis of cost saving on Biogas are as follows. $1 \mathrm{~m}^{3}$ of biogas is equivalent to $0.45 \mathrm{Kg}$ or $450 \mathrm{~g}$ of LPG. Volume of Biogas produced in Apparatus II is $3.58 \times 10^{-3} \mathrm{~m}^{3}$. The biogas produced can be analysed in terms of equivalent to LPG and then we can compute the cost saving from the produced biogas.

Table 13: Laboratory Scale Production Cost of Biodiesel (1 L capacity)

\begin{tabular}{|l|c|}
\hline \multicolumn{1}{|c|}{ Raw materials } & Products \\
\hline 1L cottonseed oil $+0.15 \mathrm{~L}$ Methanol $+10 \mathrm{~g} \mathrm{KOH}$ & $0.95 \mathrm{~L}$ ester $+0.2 \mathrm{~L}$ Glycerol \\
\hline Total cost $=$ Rs.250 & \\
\hline
\end{tabular}

Table 14: Laboratory Scale Production Cost of Biogas (20 L Capacity)

\begin{tabular}{|l|l|}
\hline \multicolumn{1}{|c|}{ Raw materials } & \multicolumn{1}{c|}{ Products } \\
\hline $0.004 \mathrm{~L} \mathrm{Glycerol}+10 \mathrm{Kg}$ Cow dung $+10 \mathrm{Kg}$ Water & $7.864 \times 10^{-3} \mathrm{~L}$ of Biogas \\
\hline If using 0.2 L Glycerol & $0.3932 \mathrm{~L}$ of Biogas can be produced \\
\hline
\end{tabular}

- $\quad$ Thus 393.21 of Biogas is equivalent to $176.94 \mathrm{Kg}$ of LPG.

- $\quad$ The produced Biogas is equal to $9 \mathrm{LPG}$ gas cylinders of $19 \mathrm{Kg}$.

- The cost of 9 LPG cylinders is Rs.13, 770 which can be compensated on the cost of Biodiesel.

Table 15: Large Scale Production of Biodiesel (1000 L Capacity Plant)

\begin{tabular}{|l|c|}
\hline \multicolumn{1}{|c|}{ Raw materials } & Products \\
\hline $1000 \mathrm{~L}$ of cottonseed oil $+150 \mathrm{~L}$ of methanol $+1 \mathrm{Kg} \mathrm{KOH}$ & $950 \mathrm{~L}+200$ L Glycerol \\
\hline Total cost $=191000$ (including Miscellaneous costs) & \\
\hline
\end{tabular}

Table 16: Large Scale Production of Biogas (10,000 L Capacity Plant)

\begin{tabular}{|c|c|}
\hline Raw materials & Products \\
\hline 200 L Glycerol + 5000 Kg Cow dung + 5000 L water & 393.2 L of Biogas \\
\hline
\end{tabular}

- $\quad$ The produced biogas is equivalent to $1,76,940 \mathrm{Kg}$ of LPG.

- $\quad$ Thus the produced biogas is equal to 9312 LPG cylinders of $19 \mathrm{KG}$.

- $\quad$ Thus the cost of one $19 \mathrm{Kg}=$ Rs.1530/-

- $\quad$ The cost of 9312 LPG cylinders=Rs.1, 42, 47,360/- 
Thus the cost of the Biogas produced in our laboratory scale production is about 13,000 rupees. By selling the biogas directly to the customers using a well planned distribution system can substitute LPG.

\section{CONCLUSIONS}

This is the first study on production of Biodiesel and Biogas from Cottonseed oil. From the experiments it is clear that the production of Biodiesel through transeseterification reaction is easy using cotton seed oil and the cotton seed waste can be used to produce Biogas which can be used to decrease the cost of the produced biodiesel.

To overcome the need of alternate fuels in the field of automobiles in upcoming years due to over population and less availability of fuels like diesel, various blends of Cottonseed oil ester and diesel were experimented.

Biogas production rate can be improved by using Glycerol as additives in Biogas digesters.

The Biogas production using by-products of biodiesel production such as Methyl ester water wash, Glycerol and Cottonseed waste is possible at low cost.

The Biodiesel cost can be reduced by utilizing the produced biogas.

The $\mathrm{B} 10$ is the blend that showed the best results on Performance and Emission tests.

B10 overcomes the environmental and other pollution factors. It is eco friendly and cost effective.

\section{REFERENCES}

1. Patni Neha et.al, Use of Sunflower and Cottonseed Oil to prepare Biodiesel by catalyst assisted Transeseterification, Research Journal of Chemical Sciences ISSN 2231-606X,Vol.3(3), 42-47, March (2013)

2. Hanumanth Mulimani, Extraction Of Biodiesel From Vegetable Oils And Their Comparisons, International Journal Of Advanced Scientific Research And Technology Issue 2, Volume 2 (April 2012) Issn: 2249-9954.

3. Ayhan Demirbas, Progress and recent trends in biodiesel fuels, Elsevier, Energy Conversion and Management 50 (2009) 14 34.

4. M. Haitl et.al, Use of G-Phase for Biogas Production, Acta Universitatis Agriculturae Et Silviculturae Mendelianae Brunensis, Volume Lx 11 Number 6, 2012.

5. Rebekkah Nelson, Methane Generation from Anaerobic Digesters: Considering different substrates.

6. Heriyanti, Addition of Esters on Anaerobic Digestion: Inhibiting or Boosting Biogas Production?, Master of Science Thesis, Department of Chemical and Biological Engineering Division of Chemical Reaction Engineering Chalmers University Of Technology Göteborg, Sweden, 2012

7. Alexander Bauer et.al, Potential Of Biogas Production In Sustainable Bio refinery Concepts, Division of Agricultural Engineering, Department of Sustainable Agricultural Systems, Experimental Farm Gross-Enzersdorf.

8. Singh Dipti et.al, Production of both esters and biogas from Mexican poppy, African Journal of Environmental Science and Technology Vol. 4(12), pp. 866-871, December 2010 Available at http://www.academicjournals.org/AJEST

ISSN 1991-637X @2010 Academic Journals.

9. Abdel-Hadi, M. A, A Simple Apparatus For Biogas Quality Determination, Misr J. Ag. Eng., 25(3): 1055- 1066 Biological Engineering. 
10. N. Jaya et.al, Kinetic Studies Of Heterogeneously Catalyzed transesterification Of Cottonseed Oil To Biodiesel, Journal of Environmental Research And Development Vol. 5 No. 3A, January-March 2011.

11. Xiaohu Fan et.al, Engine Performance Test of Cottonseed Oil Biodiesel, The Open Energy and Fuels Journal, 2008, 1, 40-45.

12. Haiying Tang et.al, Fuel properties and precipitate formation at low temperature in soy-, cottonseed-, and poultry fat-based biodiesel blends, Elsevier, Fuel 87 (2008) 3006-3017.

13. Qing Shu et.al, Synthesis of biodiesel from cottonseed oil and methanol using a carbon-based solid acid catalyst, Elsevier, Fuel Processing Technology 90 (2009) 1002-1008.

14. Giovanni Esposito, 1874-8295/12 2012 Bentham Open Open Access Bio-Methane Potential Tests To Measure The Biogas Production From The Digestion and Co-Digestion of Complex Organic Substrates, The Open Environmental Engineering Journal, 2012, 5, 1-8.

15. Nusara Sinbuathong et.al, Effect of the Solid Content on the Biogas Production from Jatropha Curcas seed cake, Proceedings of the Global conference on Global Warming.

16. Sandeep Singha et.al, Characterization of biodiesel derived from waste cottonseed oil and waste mustard oil, International Journal of Engineering Science and Technology (IJEST). 
